\title{
From the desk of Editor-in-chief
}

\author{
"May everybody witness the Global Peace."
}

The Editorial Board of Nepalese Journal of Radiology (NJR) is excited and encouraged with the successful online and hard copy release of the first and second issues of biannual NJR. The overwhelming appreciation and support received with the first and second issues of NJR have made us work harder to improve the quality of this Journal and we are much happy to announce the release of third issue of the Journal (NJR / Vol 2 / No. 2 /Issue 3 / July- Dec 2012).

Personally it's matter of pride for me to work with committed and dedicated team of Editorial board member with their continued support, I assure you for regular, timely release and improvement of NJR. The regular advice and help received by National and International advisors of NJR Editorial board has made my job much easier. I make a special note of appreciation for their hard work shown by one of our editor Mr. Arun Gupta (Radio Physicist) and Mr. Suman Pokhrel (Staff of NJR Office).

We believe that much needed demand of Journal of Radiological Sciences in Nepal has been fulfilled where all Nepalese Radiologists has great opportunity to communicate and disseminate clinical and scientific achievements in the country, in the region and to the global community of Radiological Professionals.

It is important to realize that Radiology Journal should aim to provide recent and useful information to Radiologists for its application in practice. Certainly a quality published research work will allow achieving this goal. We always believe that anonymous peer review of the articles before being accepted for the publication improves the quality of the Journal however the readers need to evaluate the scientific and methodological quality and reproducibility of the result. We believe that review articles by experts in the related field might be of more value than traditional text book. The editorial board of NJR hopes to receive such review article submission. Once we receive the article, we assure you for prompt response and peer review of your article.

NJR is aimed on receiving the articles focused on translating experience and research into clinical practice stimulating Radiologists of younger generation to conduct scientific research work and publishing their achievements.

The usefulness of the Journal/article will be judged on the basis of healthy, constructive comments and criticism which will be published in the subsequent issue of the Journal. I believe in regular and timely peered review publication and steady improvements of the Journal to achieve excellence (As said Rome is not built in a day) which will be only possible with continuous dedicated commitment and efforts of the experts of Radiological Sciences of the country. We welcome any suggestion and advice from experts across the world.

May God bless all of us! Long live Nepal Radiologists' Association. 